\title{
Adherence to amendment of the International Code of Zoological Nomenclature for articles including new names or nomenclatural acts in Ichthyological Research
}

(C) The Ichthyological Society of Japan 2012

On 4 September 2012, the International Code of Zoological Nomenclature was amended and electronic-only publications were classified as allowed publications when they satisfy several amended articles in addition to the criteria for publication shown in ICZN (1999) (ICZN 2012; see also http://www.pensoft.net/journals/zookeys/article/3944/). To satisfy the amended articles, electronic publications must state the date of publication in the work itself (Art. 8.5.2) and be registered in the Official Register of Zoological Nomenclature (ZooBank) and contain evidence in the work itself that such registration has occurred (e.g., a ZooBank registration number) (Art. 8.5.2; see also examples of Art. 5) for their availability.

The Ichthyological Society of Japan (ISJ) has discussed with Springer the matter of making Online First articles of Ichthyological Research (IR) available publications and has decided to add the following two footnotes to articles that include new names or nomenclatural acts:

This article was registered in the Official Register of Zoological Nomenclature (ZooBank) as XXXXXXX (the ZooBank registration number will be shown here); and:

This article was published as an Online First article on the online publication date shown on this page. The article should be cited by using the doi number.

These footnotes should be inserted above the addresses of the authors in the left column of the first page. After receiving an accepted manuscript, the Managing Editor registers it with ZooBank for its number. The second footnote clearly indicates the date published online, which is effective to avoid citations of its printed version lacking priority (see Art. 21.9). It furnishes notification that the Online First articles should be cited by using the doi number because they lack volume numbers and page numbers (see "Literature cited" below for an example of citation using the doi number).
Amended articles of ICZN state that the entry in ZooBank must give the name and Internet address of an organization other than the publisher which is intended to permanently archive the work in a manner that preserves the content and layout and is capable of doing so (Art. 8.5.3.1), and to assign an ISBN for the work or an ISSN for the journal containing the work (Art. 8.5.3.2). We have confirmed that IR satisfies these two criteria.

IR satisfies all criteria associated with the availability of electronic-only publications, allowing articles that include new names or nomenclatural acts to be published as Online First articles (e.g., Sasaki and Kimura 2012). This makes the period from acceptance to publication significantly shorter. We hope that many colleagues who are studying new taxa or nomenclature will submit their articles to IR as a swift vehicle to publication.

The Ichthyological Society of Japan

Seishi Kimura, President

Kunio Sasaki, Editor-in-Chief

Hisashi Imamura, Managing Editor of Ichthyological Research

\section{References}

ICZN (International Commission on Zoological Nomenclature) (1999) International Code of Zoological Nomenclature, 4th edn. International Trust for Zoological Nomenclature, London

ICZN (2012) Amendment of Articles 8, 9, 10, 21 and 78 of the International Code of Zoological Nomenclature to expand and refine methods of publication. Zootaxa 3450:1-7

Sasaki D, Kimura S (2012) Descriptions of two new silversides, Hypoatherina golanii and Hypoatherina lunata, from the IndoWest Pacific (Atheriniformes: Atherinidae). Ichthyol Res. doi: 10.1007/s10228-012-0318-7 